\title{
An unusual case of benign symmetric lipomatosis
}

Lilian Soares Couto $^{1 *}$, Leonard M. Glassman ${ }^{2}$, Poliana Lopes Parreira ${ }^{1}$, Murilo Antunes de Castro ${ }^{1}$ and Kim-Ir-Sen Santos Teixeira ${ }^{1}$

${ }^{1}$ Hospital das Clínicas da Universidade Federal de Goiás, Goiânia, Brasil

${ }^{2}$ Washington Radiology Associates, Washington, DC, USA

\section{Case report}

A 47-year-old asymptomatic woman, who came for her annual mammogram.

Mammography showed symmetric hypodense masses, with fat content, in the axillary tail process bilaterally and no other findings (Figure 1).

She presents as comorbidity, systemic arterial hypertension that is well controlled with medication use. There was no history of alcohol abuse.

The patient underwent Ultrasound (US) that not presented expressive changes (Figure 2). The Magnetic Ressonance (MR) shows ovoid masses with homogeneous imaging characteristics of fat in T1 and T2 sequences (Figure 3 ).

The clinical inspection was able to realize bulging at the site of the areas seen to mammography.

Still in the inspection, the patient had an appearance of a body with muscles well defined, but her body mass index and abdominal circumference were normal. She reported that there were others similar palpable mass on the surface of her body (eg.: abdominal wall and anterior aspect of the left forearm) (Figure 4) and that her sister and father had the same changes. She has two children, that don't have disease.

A blood count, endocrine test (cortisol, LH, FSH) and testosterone were normal. Hepatic function panel was lightly changed, without evidence of chronic liver disease. She had dyslipidemia, characterized by: total cholesterol increased and HDL reduced. Fasting glucose and triglycerides was significantly increased. Bases on these laboratorial

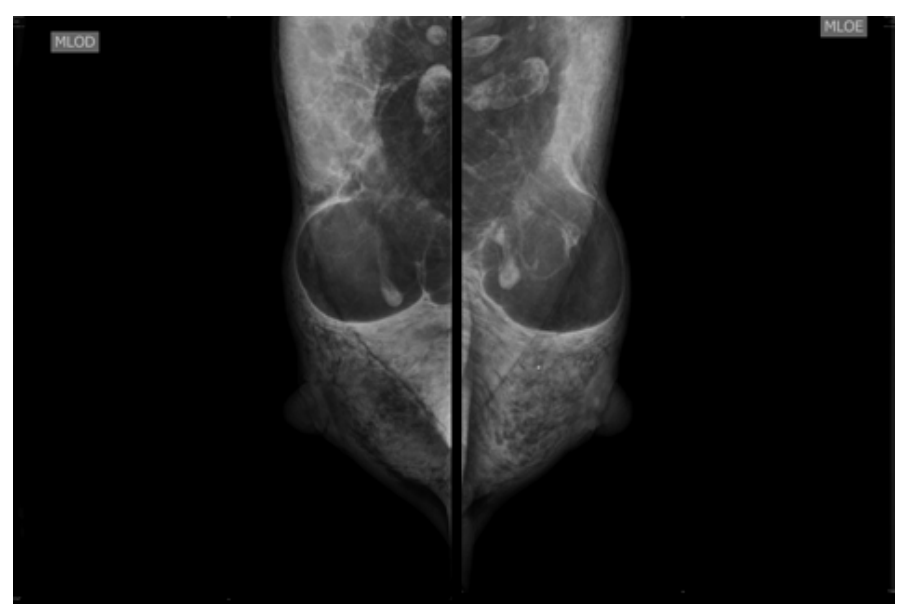

Figure 1. Mammography: hypodense masses, with fat content, in the axillary process bilateral

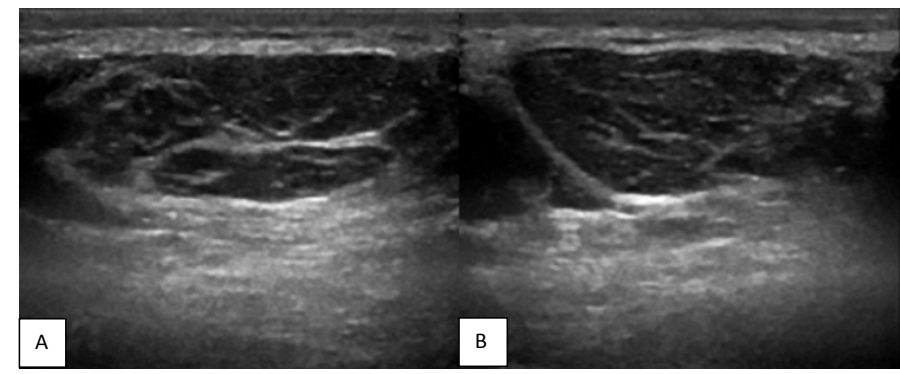

Figure 2. US: Ill-defined lipomatous masses in the axillary regions. A: right armpit. B left armpit

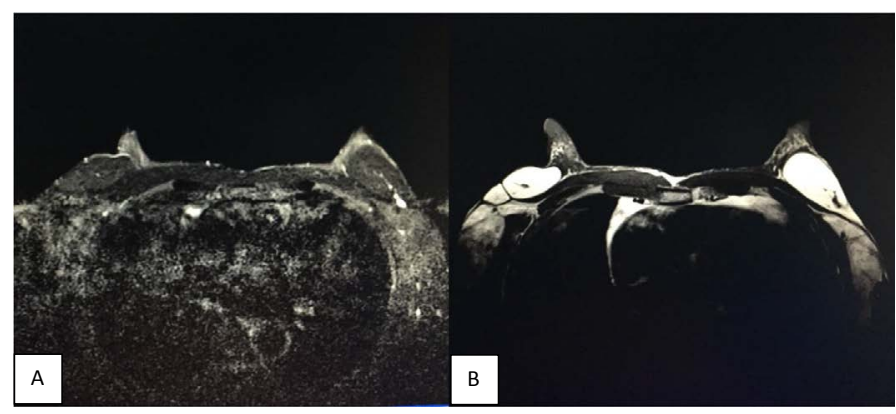

Figure 3. MR: ovoid masses with homogeneous imaging characteristics of fat. A: T2. B: T1

findings we confirm metabolic syndrome, which as we shall see later, may be related with Benign Symmetric Lipomatosis (BSL).

\section{Discussion}

Initially described by Sir Benjamin Brodie in 1846, BSL is a rare condition with an incidence of about 1 in 25.000 and a male-to-female ratio of 15:1 to 30:1 [1,2]. In the following decades, Otto Madelung, Launois and Bensaude reported the first series of patients with lipomas associated with alcoholism [3]. Therefore, it is also known as Madelung's disease, Launois-Bensaude syndrome. In general, is characterized by the growth of nonencapsulated masses of adipose tissue [4]. In the following case the masses presented a thin capsule that was difficult to visualize in the ultrasound (Figure 5).

BSL typically affects middle-aged man of mediterranean origin with a history of alcohol abuse [5,6]. Although, some cases have also been reported in young adults, women and children, even without alcohol consumption reported, like as patient.

Correspondence to: Lilian Soares Couto, Hospital das Clínicas da Universidade Federal de Goiás, Goiânia, Brasil, E-mail: liliancouto@hotmail.com

Received: May 27, 2017; Accepted: June 16, 2017; Published: June 19, 2017 
The main finding is a diffuse or circumscribed symmetrical accumulation of adipose tissue, primarily around the neck, back, shoulders and upper trunk. The lower limbs and lower trunk are rarely involved. BSL can be divided into three forms according to distribution of lipomatous masses: proximal, central and distal. The vast majority of the reports represent the proximal form, which is characterized by involvement of the neck, shoulders, and upper trunk. In the distal form, bilateral hands, feet or knees are affected. When the masses occupy symmetrically the lower trunk, arms and upper legs, it is called central form [3].

On the other hand, some authors also divided BSL in two distinct patterns of fatty tumours distribution. The type I showed wellcircunscribed, grossly round masses protruding from the body surface, primarily observed in men, while the type II presented with an obesitylike appearance due to diffuse involvement of the subcutaneous layer and affect both men and women [5,7]. In males, symmetrical masses of fat affecting the neck and shoulders similar to a "horse collar" was also reported [8]. Thus, there is a specific morphological aspect in female patients with BSL, characterized by similar appearance to obesity and low occurrence of the typical Madelung's collar. The reported patient had a body mass index and abdominal circumference normal, which is not as common for women with the disease.

In some patients, the distribution of adipose tissue can provide the appearance of a body with well-defined muscles, classically named pseudoathletic form of Launois and Bensaude syndrome, like as the reported [8].

The cause of BSL is still unknown. However, alcoholism (60\% to $90 \%$ of patients) and some metabolic disturbances (abnormal glucose tolerance; excessive secretion of insulin; hyperuricemia; dyslipidemia; renal tubular acidosis; alterations in liver enzyme levels; abnormal function of glands (thyroid, adrenal, pituitary); and abnormal testicular function) have been associated with the disease $[3,5]$. The laboratorial exams diagnosed the reported patient with dyslipidemia and metabolic syndrome.

The diagnosis is usually made based on clinical findings, disease history (in the present case, the patient reported confirmed others familial cases of an "athletic appearance") and imaging exams that shows symmetrical adipose mass accumulation.

Biopsy of fatty mass could be performed to confirm definitive diagnosis [4].

BSL could be complicated by somatic and autonomic neuropathy and by the infiltration of the adipose tissue at the mediastinal level. The extension of the lipomatous tissue around the upper airways associated with compression or dislocation of deeply located mediastinal structures, responsible for dysphagia, snoring and obstructive sleep apnea syndrome [5]. Our patient underwent chest Computed Tomography (CT), which was normal (Figure 6).

\section{Conclusion}

The reported case is a rare presentation of Madelung's disease, since pseudoathletic body form is more common in males and is strongly associated with alcohol use. It is believed this condition is underdiagnosed due to the absence of specific criteria. However, it tends to be confirmed based on clinical data, family history and compatible image studies. This diagnosis is especially important for related comorbidities, such as metabolic syndrome, which can be treated in order to reduce morbidity and mortality of these patients.

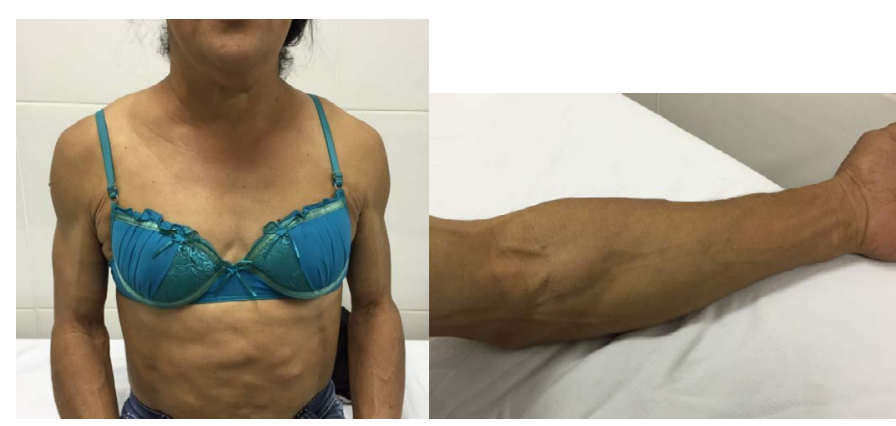

Figure 4. Appearance of a body with muscles well defined and others similar palpable masses on the surface of her body

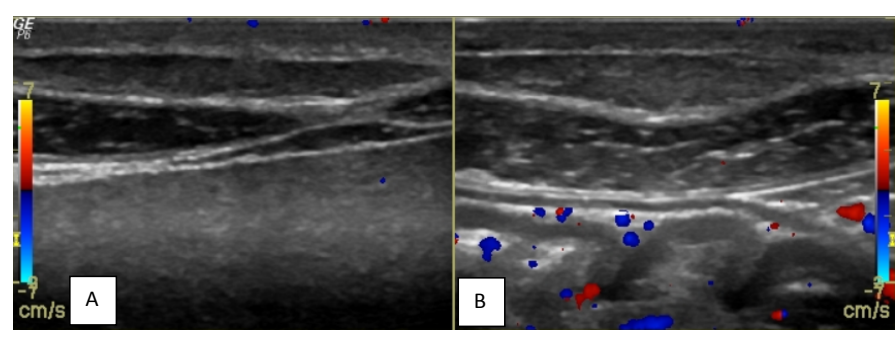

Figure 5. US: ill-defined lipomatous masses in abdominal wall. A: right hypochondrium. B: left hypochondrium

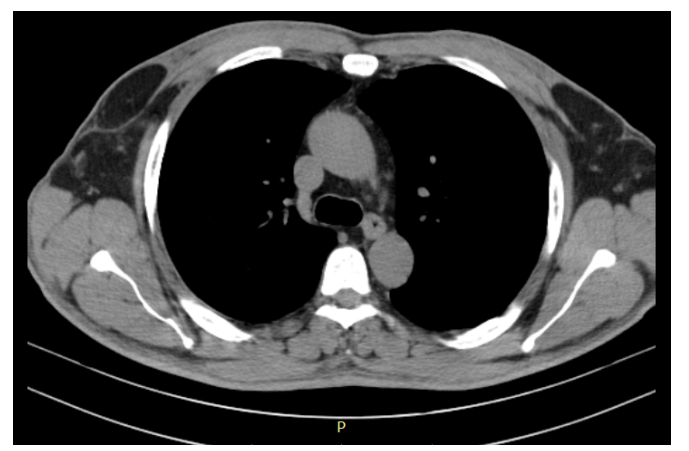

Figure 6. CT - mediastinal structures and air way are normal. Hypodense mass in axilary process bilateral.

\section{References}

1. Enzi G, Busetto L, Sergi G, Coin A, Inelmen EM, et al. (2015) Multiple symmetric lipomatosis: A rare disease and its possible links to Brown adipose tissue. Nutr Metab Cardiovasc Dis 25: 347-53. [Crossref]

2. Meyer TN, Meyer GPN (2007) Atypical case of multiple symmetrical lipomatosis. Rev Soc Bras Cir Plast 22: 64-66.

3. Tekin A, Ogetman Z (2009) Central form of multiple symmetric lipomatosis: a case report. Cases J 2: 8427. [Crossref]

4. Mimica M, Pravdic D, Nakas-Icindic E, Karin M, Babic E, et al. (2013) Multiple Symmetric Lipomatosis: A Diagnostic Dilemma. Case Rep Med. [Crossref]

5. Busetto L, Strater D, Enxi G, Coin A, Sergi G, et al. (2003) Differential clinica expression of multiple symmetric lipomatosis in men and women. Int $J$ Obes Relat Metb Disord 27: 1419-1422. [Crossref]

6. Mevio E, Sbrocca M, Mullace M, Viglione S, Mevio N (2012) Multiple Symmetric Lipomatosis: A Review of 3 Cases. Case Rep Otolaryngol. [Crossref]

7. Pandzic Jaksic V, Stoos Veic T (2008) Multiple Symmetric Lipomatosis Type 2 in Females - Report of Two Cases. Acta Dermatovenerol Croat 16: 31-34. [Crossref]

8. Gon Airton dos Santos, Minelli Lorivaldo, Mendes Mauro Filgueiras (2005) Benign symmetric lipomatosis. An Bras Dermatol 80: 543-544.

Copyright: (C2017 Couto LS. This is an open-access article distributed under the terms of the Creative Commons Attribution License, which permits unrestricted use, distribution, and reproduction in any medium, provided the original author and source are credited. 